BOOK AND MEDIA REVIEW

\section{Eradicating Female Genital Mutilation: A UK Perspective}

Hilary Burrage. London, UK: Ashgate, 2015. ISBN-13: 978-1-472-41994-1. Price: $£ 25.00$. Pages: 341 (paperback)

Eradicating Female Genital Mutilation provides an insightful and thorough discussion of the problems facing women in the UK who have encountered female genital mutilation (FGM), and is an excellent book. The author, who is not a clinician but a sociologist with extensive experience of working in areas such as teenage pregnancy and health and social care as a senior lecturer, comprehensively explores the problem of FGM.

The book is divided into 12 chapters covering demography, perceptions and beliefs, power, clinical issues including mandatory reporting, legislation and governance, prevention and politics. The book is fully referenced throughout. The first four chapters address why FGM happens, from both religious and cultural viewpoints. The author discusses the socioeconomic reasons for continuing the practice of FGM, and the tensions this causes within a changing world involving secret societies that help to facilitate the practice. Chapter 5 addresses clinical issues and the care of women, aspects of the physical examination, the difficulties of mandatory reporting, and the dilemmas faced by health professionals. The final six chapters address the legislation and prevention of FGM, discussing in detail public perception, FGM tourism, punishment and policing, false accusations and reprisals. For those who have anxieties about this area, this book tries to address many of the concerns of the health professional who is responsible for identifying and managing FGM. Finally, the author turns her attention to the victims, survivors and perpetrators of FGM, and the eradication of this practice. The book ends by examining political and funding issues, compassion fatigue and how these might be resolved. This is a book that makes one consider the issues surrounding FGM and the challenges facing health professionals.

This is an interesting and very readable book, which provides background and insight, and which would be suitable for anyone interested in this topic, health professionals working within sexual health, and anyone involved in teaching this topical and emotive subject. Reviewed by Su Everett ${ }^{1,2}$

${ }^{1}$ Senior Lecturer, Middlesex University, London, UK; s.everett@mdx.ac.uk

${ }^{2}$ Senior Nurse Practitioner, Marlborough Clinic, Royal Free Hospital, London, UK

Competing interests None declared.

\section{Provenance and peer review}

Commissioned; internally peer reviewed.

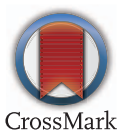

Published Online First 28 July 2016

J Fam Plann Reprod Health Care 2016:42:300 doi:10.1136/jprhc-2016-101583 